\title{
SINFONIA DAS PAIXÕES: A RELAÇÃO ENTRE MÚSICA E SENTIMENTO NA OBRA DE EDUARD HANSLICK
}

Felipe Thiago dos Santos

Em face das teorias estéticas datadas do século XIX o compositor Hanslick aponta para o seguinte problema principal de sua obra:

\begin{abstract}
"A música tem que tratar dos sentimentos". Este "ter que tratar" é uma das expressões características da estética musical atual. Em que consiste a conexão da música com os sentimentos, de determinadas peças musicais com determinados sentimento; por quais leis da natureza ela age, por quais leis da arte ela se configura - sobre isso, deixam-nos completamente no escuro aqueles que tinham que "tratar" disso. (HANSLICK. E. 1922. p. 4). ${ }^{1}$
\end{abstract}

Na passagem referida "aqueles" são todas as estéticas que tratam da música, de Wackenroder a Wagner, de um ponto de vista metodológico que parte da impressão subjetiva da fruição musical para, apenas depois, tratar da própria música. Mesmo na época de Hanslick "o belo musical continua a ser considerado apenas quanto ao aspecto de sua impressão subjetiva..." (HANSLICK. 1989. p. 15). A tarefa que o crítico musical se pretende é a de inverter essa lógica de análise e conduzir a pesquisa em torno da estética musical para o mesmo modo de investigação que as pesquisas nas artes literárias e plásticas já se propunham, a saber, aquela que se fundamenta na concepção de que "[...] a primeira coisa a ser estudada é o objeto belo e não o sujeito dotado de sensações" (IBID). Portanto, é necessário para Hanslick procurar na música o que faz dela uma arte bela, indiferente das condições psicológicas daqueles a quem ela se dirige. Essa premissa de teor científico vai ao encontro do método usado pelas ciências naturais que, em última análise se pretende "[...] examinar o que há de duradouro e objetivo" no seu objeto de estudo, “[...] prescindindo das milhares impressões subjetivas” (IBID. p.

\footnotetext{
${ }^{1}$ „Die Musik hat es mit den Gefühlen zu tun“. Dieses „zu tun haben“ ist einer der charakteristischen Ausdrücke der bisherigen musikalischen Ästhetik. Worin der Zusammenhang der Musik mit den Gefühlen, bestimmter Musikstücke mit bestimmten Gefühlen bestehen, nach welchen Naturgesetzen er wirk, nach welchen Kunstgesetzen er zu gestalten sei, darüber ließen uns diejenigen vollkommen in Dunkel, die eben damit ,zu tun “ hatten. (Tradução nossa).
} 
14). Diferentes dos sistemas metafísicos que partem sempre de uma premissa universal para o belo e, apenas posteriormente, se referem ao objeto artístico em sua particularidade, "Hanslick argumenta em favor de uma teoria artística própria da música, que no modo de falar não seja nada inferior ao pensamento das ciências naturais e se constitua sobre as formas estruturais da música" (GRENZDÖRFFER. p. 3). ${ }^{2}$

Dado as bases de seu modo de investigação, Hanslick passa a submeter a interrogatório os principais elementos constituintes das estéticas musicais, principalmente aqueles que servem de motivo par que se possa, supostamente, encontrar no sujeito o material da análise a ser estudado. A começar pelo papel dos sentimentos na música: "Por um lado, é estabelecido enquanto finalidade e determinação da música que ela deva despertar sentimentos (Gefühle) ou 'belos sentimentos'. Por outro lado, designam-se os sentimentos enquanto conteúdo (Inhalt), que é representado pela música em suas obras. (HANSLICK. 1922. p. 5)."3Portanto, trata-se de refutar a ideia de que os sentimentos são, de um lado, a finalidade e, de outro, o conteúdo da música. Começamos pela primeira. Hanslick afirma que o prazer, tal como o sentimento provocado pela música ou mesmo por qualquer arte não tem relação alguma com o belo do objeto mesmo. Uma vez que a beleza se define como forma nua (bloss Form), os sentimentos se tornam um objetivo de segunda ordem, visto que eles não têm a necessidade de ser alcançados. O objetivo maior da música é apresentar essa forma nua e, ainda que sentimentos, prazer ou desprazer, surjam desse primeiro e maior objetivo, eles “[...] não dizem respeito ao belo enquanto tal” (1989. p. 16). Pois, mesmo sem suscitar qualquer sentimento, o belo "é e continua sendo belo [...] somente para o prazer de um sujeito que o contempla, e não a causa desse prazer" (IBID. 17).

Para fundamentar essa posição Hanslick diferencia os conceitos de "sentimento" (Gefühl) e "sensação" (Empfindung). A sensação é, justamente, a percepção de uma determinada qualidade sensível (Wahrnehmen einer bestimmten Sinnesqualität), ou seja, quando se tem uma sensação, ocorre uma percepção sensual de uma qualidade proveniente de algo externo a mim, algo que acontece, por exemplo, quando ouvimos um som ou olhamos para uma cor. Já o sentimento é o "conscientizar-

\footnotetext{
${ }^{2}$ Hanslick plädiert für eine der Musik eigene Kunsttheorie, die den naturwissenschaftlichen Gedanken der objektiven Sprechweise in nichts nachstehe und sich auf formelle Strukturen der Musik bezieht. (Tradução nossa).

${ }^{3}$ Fürs erste wird es als Zweck und Bestimmung der Musik aufgestellt, sie sollte Gefühle oder schöne Gefühle erwecken. Fürs zweite bezeichnet man die Gefühle als den Inhalt, welchen die Tonkunst in ihren Werken darstellen. (Tradução nossa).
} 
se de uma exigência ou de uma inibição de nosso estado da alma" (Bewusstwerden einer Förderung oder Hemmung unseres Seelenzustandes. 1922. p. 6). Assim, quando sou assolado por estados da alma, como melancolia ou alegria, “[...] experimento um sentimento" (1989. P. 17), ou seja, um tornar-se consciente de um estado interno. Percebe-se que Hanslick utiliza o mesmo vocabulário kantiano, já que Kant define a sensação como “[...] uma representação objetiva dos sentidos” e sentimento como “[...] aquilo que sempre tem de permanecer simplesmente subjetivo, e que absolutamente não pode constituir nenhuma representação de um objeto" (1993. p. 51). ${ }^{4}$

A importância desta distinção vigora no fato de o belo atingir, primeiramente, nossos sentidos (Sinne) e não nossa alma (Seele). Segundo Hanslick “[...] a sensação é início e condição do prazer estético e constitui a base do sentimento” (1989. p. 18), contudo não há uma exclusividade nessa condição, pois tudo que é externo a nós atinge nossas sensações. Isso ocorre, pois, “[...] enquanto faculdade ou disposição de receber impressões, a sensação possui um caráter indeterminado e genérico, ela representa o entrelaçamento da arte com o sensível. [...] Para que seja possível um sentir, observa o autor, é necessário que haja, antes, um ouvir" (HARTMANN. 2004. p. 67). Portanto, ao defender que os sentimentos constituem a base do belo musical, a maior parte das teorias estéticas despreza, segundo Hanslick, a própria constituição fisiológica dos ouvintes. Se, ainda, a porta de entrada do belo musical passa por disposições sensíveis, logo, o critério de análise deve levar em conta não apenas o conteúdo do objeto artístico, como também esse próprio aparato receptivo corporal. Mas, se os sentimentos não podem servir como critério do belo musical e, por outro lado, a sensação é apenas um primeiro momento fisiológico de recepção do material sonoro, qual seria o meio pelo qual entramos em contato com o belo? Para Hanslick: a fantasia, "[...] enquanto atividade da pura contemplação" (1922. p. 7. Tätigkeit des reinen Schauens). No entendimento de Hanslick há uma comunicação entre a fantasia do artista e a fantasia do ouvinte. Definindo-a enquanto uma contemplação com intelecto (Verstand), isto é, um amalgama de representações e juízos, Hanslick afirma que a fantasia se encontra em dois ambientes da experiência musical, por um lado ela encontra sua matéria presente nas sensações (os sons que nos acometem), mas, por outro lado, ela "[...] transmite seus raios de modo veloz sobre a atividade do intelecto e do sentimento" (IBID. p. 8). O termo usado por Hanslick é o mesmo que por Hegel. No início de suas Preleções sobre

\footnotetext{
${ }^{4}$ KANT. I. Crítica da faculdade do juízo. Rio de Janeiro: Ed. Forense Universitária. 1993.
} 
a estética, Hegel mostra que a obra de arte, oriunda de um espírito, ou seja, da subjetividade do artista, vai ao encontro da intuição e do sentimento do público (HEGEL. p. 362). ${ }^{5}$ A fantasia é definida, por Hegel, justamente como essa atividade do artista que gera a obra de arte. Hanslick, tomando de empréstimo a noção hegeliana de fantasia, mostra que essa atividade não é passiva, nem no artista e tampouco no ouvinte.

A noção de fantasia é mais um argumento usado por Hanslick para mostrar que os sentimentos não são a finalidade da música, pois "toda verdadeira obra de arte estabelecerá uma relação qualquer com nosso sentimento, mas nenhuma de modo exclusivo" (1922. p. 11) ${ }^{6}$, pois, como mostra Mario Videira: "Tal como ocorre em qualquer outra arte, também a música tem um efeito apenas secundário sobre o sentimento. Tal como ocorre em qualquer outra arte, a música somente atua do modo imediato sobre a fantasia do ouvinte". (2006. p. 110)7 . E, ainda que os sentimentos fossem o objetivo da música, seria impossível estabelecer uma relação única, pois a audição musical está sujeita a momentos históricos.

Uma vez mostrado os argumentos de Hanslick contra a ideia de que os sentimentos são a finalidade da música, passemos agora a demonstrar a refutação do autor a despeito da polêmica dos sentimentos serem (ou não) o conteúdo da música. No início do segundo capítulo de Do belo musical, Hanslick nos mostra que existe uma relação direta entre o conteúdo de uma arte com a matéria pela qual ela será composta. Dessa forma, "toda arte possui um círculo de ideias, que ela representa pelos seus meios de expressão como som, palavra, cor, pedra" (1922. p. 20) ${ }^{8}$, ou seja, as condições de utilização desses meios, tal como a efetivação da obra a partir destes materiais serão os dados pelos quais se instaura o conceito de beleza. Um poeta tem como matéria prima as experiências vividas e não vividas, seu meio será o da palavra e do conceito, assim como um pintor toma do mundo sua matéria, como uma árvore, uma pessoa, um lugar, etc. e, através das cores ele representa esse material. O material que a música se utiliza tem, sem dúvidas, um grau de determinação menor do que o das outras artes, uma vez que não se pode exprimi-lo com palavras ou imagens. Desde o fim do Século XVIII já se fundamentava que o som não precisava de referencial, pois não se pode concebê-lo

\footnotetext{
${ }^{5}$ HEGEL, G. W. F. Werke. Frankfurt/Main: Suhrkamp. 1970.

${ }^{6}$ Jedes wahre Kunstwerk wird sich in irgendeine Beziehung zu unsern Fühlen setzen, keines in eine ausschließlich. (Tradução nossa).

${ }^{7}$ VIDEIRA. M. O romantismo e o belo musical. São Paulo: Editora Unesp. 2006.

${ }^{8}$ Jeder Kunst eignet ein Kreis von Ideen, welchen sie mit ihren Ausdruckmitteln als Ton, Wort, Farbe, Stein darstellt. (Tradução nossa).
} 
enquanto uma determinação concreta, isto é, numa música cada som é sucedido por outro e, assim, num transcorrer contínuo, por isso, é a arte mais subjetiva de todas. Daí Hanslick afirmar que essa característica foi responsável para que se atribuísse “[...] como conteúdo da música a escala completa de sentimentos humanos” (1989. p. 32). As estéticas colocavam como prerrogativa da música a imitação ou representação dos sentimentos, visto que esses possuem, tal como a música, um aspecto evidentemente mais vago do que a precisão conceitual. Moldou-se, assim, a ideia de que "[...] os sons e sua concatenação artística não passam de mero material, o meio de expressão com que o compositor representa o amor, a coragem, o fervor religioso, o enlevo." (IBID).

Para Hanslick há um erro crucial no alicerce deste pensamento: “[...] sentimentos não estão isolados na alma a ponto de poderem ser extraídos de dentro dela por uma arte, à qual é vedada a representação de outras atividades espirituais” (IBID. p. 33). Não há, portanto, uma exclusividade espacial dos sentimentos na subjetividade humana, tal como não há a possibilidade de se determinar os sentimentos através dos efeitos que eles causam no sujeito. Ao contrário disso, Hanslick afirma que os sentimentos são “condicionados por representações, juízos, enfim, por todo o conjunto do pensamento intelectual e racional, a que se costuma contrapor o sentimento como algo antagônico". (IBID). Há, portanto, uma relação interdependente entre sentimentos, juízos, representações e conceitos. Não podemos dizer o que é o ódio através de uma perturbação fisiológica, mas, quando sujeitamos o ódio à representações e juízos, isto é, a um aparato conceitual, daí podemos definir (do ponto de vista conceitual) o que ele é, ou, nas palavras de Hanslick: “o sentimento de esperança é inseparável da representação de um estado futuro mais feliz, que se compara com o estado presente". (IBID). A própria argumentação das estéticas que defendem a tese de os sentimentos serem o conteúdo da música se perde em sua fadada dissonância, pois elas mesmas já afirmam que os conceitos estão fora do domínio constitutivo da música. A música, como mostrou Hanslick, é incapaz de tomar para si a representação dos conceitos, pois esses são de ordem diferente, por outro lado, só pode haver uma determinação dos sentimentos, quando se os sujeitam a um vocabulário conceitual, isto é, “[...] a determinação dos sentimentos repousa em seu núcleo conceitual" (1922. p. 23) ${ }^{9}$, por isso, à música não cabe representar sentimentos, assim como estes não podem ser definidos como o conteúdo da música.

\footnotetext{
${ }^{9}$ Die Bestimmtheit der Gefühle ruht ja gerade in deren begrifflichem Kern. (Tradução nossa).
} 
Limitado ao material que é próprio da sua arte, o compositor está fadado a criar a partir de ideias puramente musicais, nada além disso. Em outras palavras, se o pintor trabalha com as cores, os contornos, etc. o compositor aplica seu conhecimento sobre “[...] variações de força, movimento, proporções, assim como a ideia do crescer, desvanecer, do acelerar, do hesitar, do entrelaçamento artificial, da simples progressão etc.” (IBID. p. 24) ${ }^{10}$. Sobre essas ideias musicais só são possíveis adjetivos que sejam semelhantes a elas, como suave (sanft), agressiva (heftig), graciosa (zierlich), entre outros. Segundo Hanslick, “[...] as ideias que o compositor representa são, antes de tudo, puramente musicais" (IBID. 25) ${ }^{11}$, elas remetem às ideias mais gerais, por isso uma música lenta traz mais relativamente viva a ideia geral de algo suave, tal como ocorre nas outras artes, “[...] mas com uma interpretação incomparavelmente mais inverta e arbitrária”. (1989. p. 36).

Para Hanslick a ideia de uma relação intrínseca entre certas estruturas sonoras, tal como os modos de efetivação dinâmica (o adágio, allegro, moderato, etc.) com os sentimentos é, no mínimo, duvidosa. Ainda que haja uma identificação dos processos internos de ouvinte com os elementos componentes da música, a única coisa que é possível representar seria “[...] somente a própria dinâmica” (1989. p. 37) dos sentimentos. Como mostra Dahlhaus em Die Idee der Absoluten Musik: "[...] a não determinação do objeto (Gegenstandslosigkeit) e a abstração (Abstraktheit) da expressão musical, que permanece limitado à música, constitui a dinâmica dos sentimentos. Mas o sentimento mesmo não pode ser o conteúdo da música" (DAHLHAUS. p. 76).

Hanslick assume que os elementos musicais já possuem em si um significado. Tal como ocorre com as cores, “[...] também os sons possuem em principio e isoladamente, um significado simbólico, que atua externamente e antes de qualquer intenção artística" (1989. p. 38). Aqui o autor está se referindo às diversas teorias a respeito das cores, que tentavam associar certas cores a determinados sentimentos. Mas, ainda que haja um significado natural para uma cor ou para um som, essa naturalidade simbólica é anulada quando esses elementos se configuram em obra de arte, por isso, “[...] num quadro histórico, um vermelho qualquer não significa para nós alegria, ou

${ }^{10}$ [...] Veränderung der Kraft, der Bewegung, der Proportionen sich beziehen, aos die Idee des Anschwellenden, des Absterbenden, des Eilens, Zögerns, des künstlich Verschlungen, des einfach Fortschreitenden u. gdl. (Tradução nossa).

${ }^{11}$ Die Idee, welche der Komponist darstellt, sind vor allem und zuerst rein musikalisch. (Tradução nossa). 
branco, inocência, tampouco numa sinfonia um tom qualquer de lá bemol não despertará em nós um estado de espírito entusiástico” (IBID. p. 39). O simbolismo das cores e dos sons será, em última análise, apenas uma interpretação, nunca possuindo uma referência natural independente do lugar onde estiver. Usando de exemplo a abertura de Prometheu de Beethoven, Hanslick mostra uma análise musical: parte-se de uma queda do C (Dó) para sua quarta inferior, o $\mathrm{G}$ (Sol), e segue-se esse movimento por alguns compassos criando, assim, um fraseado melódico simétrico. Esse tema não é passível de uma interpretação sentimental, pois os elementos que o constitui são "apenas" musicais. Sua beleza não pode ser caracterizada, para Hanslick, por despertar (ou não) certos sentimentos, mas, ao contrário, a sua beleza reside na forma como a harmonia e melodia se nos apresentam dentro de uma pulsação rítmica.

Hanslick, mas uma vez supondo a possibilidade de ser os sentimentos o conteúdo da música, apresenta sua crítica com relação a universalidade desses sentimentos despertos. Ainda que ocorresse, de fato, uma representação dos sentimentos pela música, como seria concebível que esse conteúdo tivesse uma validade universalizante. Desta forma, “quem ousará apontar um determinado sentimento como conteúdo desses temas? Um dirá 'amor'. É possível. Outro, 'saudade'. Talvez. Um terceiro sentirá um 'fervor religioso'. Ninguém poderá contradizê-lo” (IBID. p. 43). As definições se perdem num mar de ambiguidades, incertezas e desacordos, por isso, não é possível que a música represente (darstellen) os sentimentos, pois, para Hanslick, representar significa; "produzir de modo claro e detalhado um conteúdo, 'colocá-lo diante de nossos olhos" (1922. p. 33).

A suposta ideia de que a música tem como conteúdo os sentimentos já submeteu a história, para Hanslick, às maiores controvérsias possíveis. Uma das mais conhecidas, apresentadas em Do belo musical, é a observação de Boyé em L'expression musicale mise au rang des chimères de que uma melodia (a ária de Orfeu, ópera de Gluck), se adapta de maneira idêntica, diferente da forma que se interpretava na época, a um sentimento de alegria e de tristeza. Assim, a passagem da ária citada acima se utiliza das palavras:

J'a perdu mon Eurydice (eu perdi minha Eurydice)

Rien n'egale mon malheur (nada supera meu infortúneo)

Quando podemos, na opinião de Boyé, adaptá-las às palavras: 
J'ai trouvé mon Eurydice, (eu encontrei minha Eurydice)

Rien n'egale mon bonheur (nada supera minha felicidade)

O exemplo acima serve a Hanslick para mostrar que, mesmo na música vocal, os sentimentos são guiados pelas palavras pelas quais o compositor compõe sua música. A música mesma jamais trará em si um conteúdo sentimental determinado, pois qualquer que seja o conteúdo que as palavras tragam as melodias e as harmonias sempre serão, assim, adaptadas ao texto. Portanto, qualquer motivo musical e qualquer tema podem ser adaptados a qualquer sentimento. Na própria história da música é possível perceber esse molde de adaptação. Hanslick resgata as fontes que originaram muitas peças de $O$ messias de Händel e nos mostra a origem profana desta de fervor religiosos. A partir dos madrigais de Mauro Ortensio, Händel compôs alguns duetos, no segundo deles é possível se ler: "amor cego, beleza cruel" (cieco amor, crudel beltá). Hanslick aponta que "Händel, mantendo-a inalterada na tonalidade e na melodia, utilizou para o coro da primeira parte do $O$ messias: 'pois uma criança nasceu' (1989. p. 49. denn uns ist ein Kind geboren)".

À música não cabe, portanto, representar sentimentos e, além disso, nem mesmo tomá-los como objetivo. Assim, "a música só pode tentar imitar o fenômeno exterior, jamais o sentimento específico que ele nos provoca" (IBID. p. 50). Para Hanslick os fenômenos externos são passíveis de serem representados pela música pois possuem uma dinâmica. "Mediante velocidade e ritmo dos sons, proporciona-se ao ouvido uma figura cuja impressão acústica tem com a determinada percepção visual aquela analogia que pode existir entre sensação de natureza diversa" (IBID). Foi possível, assim, que Vivaldi conseguiu imitar o canto dos passarinhos se utilizando, no primeiro movimento da primavera de As quatro estações, dos trilos do violino. Identificar na dinâmica desses sons extraídos pelo violino uma analogia com o cantar dos pássaros é possível, já “[...] querer representar com sons o 'sentimento”" (IBID. p. 51) o que provoca em nós o canto dos pássaros, isso já seria algo, para Hanslick, "simplesmente risível" (IBID).

\section{BIBLIOGRAFIA}

DAHLHAUS. C. Die Idee der absoluten Musik. Basiléia: Verlag Bäarenreiter, 1994.

GRENZDÖRFFER. K. Eduard Hanslicks Musikästhetik. In: Sound Studies. Seminararbeit. Universität der Künst. Berlim. 2008. 
HANSLICK. E. Do Belo Musical. Trad. N. Simone Neto. Campinas: Editora Unicamp, 1989.

Vom musikalisch-Schönen: Ein Beitrag zur Revision der Ästhetik der Tonkunst. Darmstadt: Wissenschaftliche Buchgesellschaft, 1922.

HEGEL, G. W. F. Werke. Frankfurt/Main: Suhrkamp. 1970.

KANT. I. Crítica da Faculdade do Juízo. São Paulo: Editora Forense Universitária, 2005.

VIDEIRA. M. O romantismo e o belo musical. São Paulo: Editora Unesp. 2006. 